\title{
Systemic design and modelling of a coiled rotor synchronous motor dedicated to electric traction
}

\author{
Aicha Khlissa, Houcine Marouani, Souhir Tounsi \\ School of Electronics and Telecommunications of Sfax, Sfax University, Sfax, Tunisia \\ Email address: \\ aichakhlissa@gmail.com (A. Khlissa), Houcine.marouani@isecs.rnu.tn (H. Marouani), souhir.tounsi@isecs.rnu.tn (S. Tounsi)
}

\section{To cite this article:}

Aicha Khlissa, Houcine Marouani, Souhir Tounsi. Systemic Design and Modelling of a Coiled Rotor Synchronous Motor Dedicated to Electric Traction. American Journal of Electrical Power and Energy Systems. Special Issue: Design, Optimization and Control of Electric Vehicles: (DOCEV). Vol. 4, No. 2-1, 2015, pp. 1-7. doi: 10.11648/j.epes.s.2015040201.11

\begin{abstract}
In this paper, we present a methodology of design and modeling of the controlling parameters of synchronous motor with wound rotor, based on the analytical method. This methodology ensures a wide operating speed range of electric vehicles. It takes into account several physical and technological constraints. The model is highly parameterized and quickly helps to provide the dimensions and power train controlling parameters values by varying the mechanical characteristics of the vehicle. It is compatible with all brands of electric vehicle power with single motor. The analytical modeling approach is validated entirely by the finite element method.
\end{abstract}

Keywords: Coiled Rotor Motor, Analytic Design, Controlling Parameters, Systemic Control, Electric Vehicles

\section{Introduction}

The production of electric vehicles in large series generally suffers from relatively high costs compared to internal combustion vehicles. For this reason, our choice was directed to a structure of synchronous wound rotor motor with smooth pole (MSRB) to reduce the cost of electric vehicle, because this type of motor is with reduced cost compared to other structures of electric motors. Indeed, the engine is in a structure easy to realize, and it is with open and straight slots and concentrated winding easy to achieve. Therefore, it has a greatly reduced manufacturing cost compared to other engine structures. It has no magnets also leading to a reduction of the cost of vehicles.

In this context, this paper presents a design methodology and modeling of control parameters of the studied motor structure.

\section{Motor Structure}

The MSRB machine is built with the same radius for the stator and the rotor. The slots directed towards the motor's center. Three design ratios define the motor's structure [1], [2] and [3]..

The first coefficient is the ratio $\beta$ of the magnet average angular width by the pole pitch $(\mathrm{L}=\pi / \mathrm{p})$. It adjusts the magnet width in versus the poles number chosen.

The second coefficient $(\alpha)$ is the ratio of the main tooth average angular width by the average angular width of a magnet. It adjusts the main tooth size and has a strong influence on the electromotive force waveform.

The last coefficient $\left(\mathrm{r}_{\mathrm{did}}\right)$ fixes the inserted tooth size. It's the ratio of the main tooth average width by an inserted tooth average width.

The advantage of these coefficients is to define quickly machine shape. However, they are based on the average radius and it is necessary to compute and check higher and lower angles teeth in order to avoid any intersection.

Table 1 illustrates the values of these coefficients:

Table 1. Values of the motor parameters

\begin{tabular}{llllll}
\hline Designations & $\boldsymbol{\beta}$ & $\boldsymbol{\alpha}$ & $\mathbf{r}_{\text {did }}$ & $\mathbf{p}$ & $\mathbf{N}_{\mathbf{d}}$ \\
\hline Trapezoidal configuration & 1 & 1 & 0.2 & 4 & 6 \\
\hline
\end{tabular}

The MSRB structure is illustrated by figure 1 : 

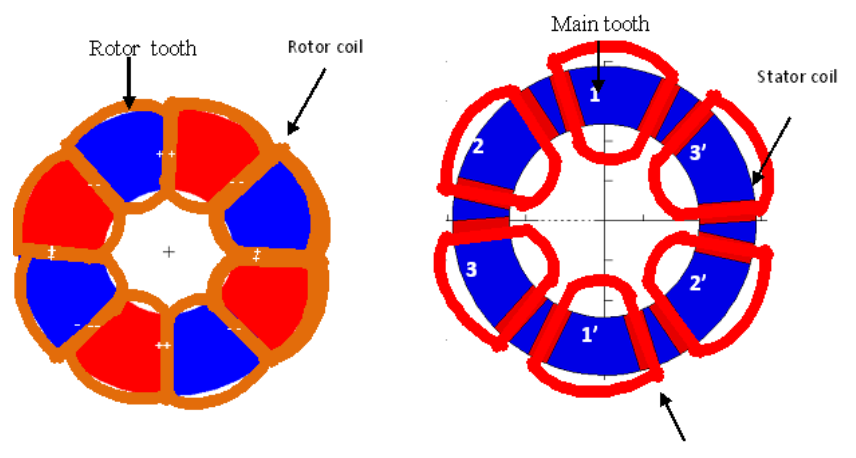

Figure 1. MSRB structure.

\section{Dimensioning Torque}

The sizing torque is calculated at the time of startup of the vehicle, where the current drawn by the motor is maximum. At this time, only the moment of inertia and torque of the vehicle due to gravity force are significant. The discretization of the movement equation at startup leads to the following sizing torque:

$$
\mathrm{C}_{\mathrm{dim}}=\frac{\mathrm{R}_{\mathrm{r}} \times \mathrm{M}_{\mathrm{v}}}{\mathrm{r}_{\mathrm{d}}} \times\left(\frac{\mathrm{V}_{\mathrm{b}}}{\mathrm{t}_{\mathrm{d}}}+\mathrm{g} \times \sin (\lambda)\right) \times \alpha_{\mathrm{t}}
$$

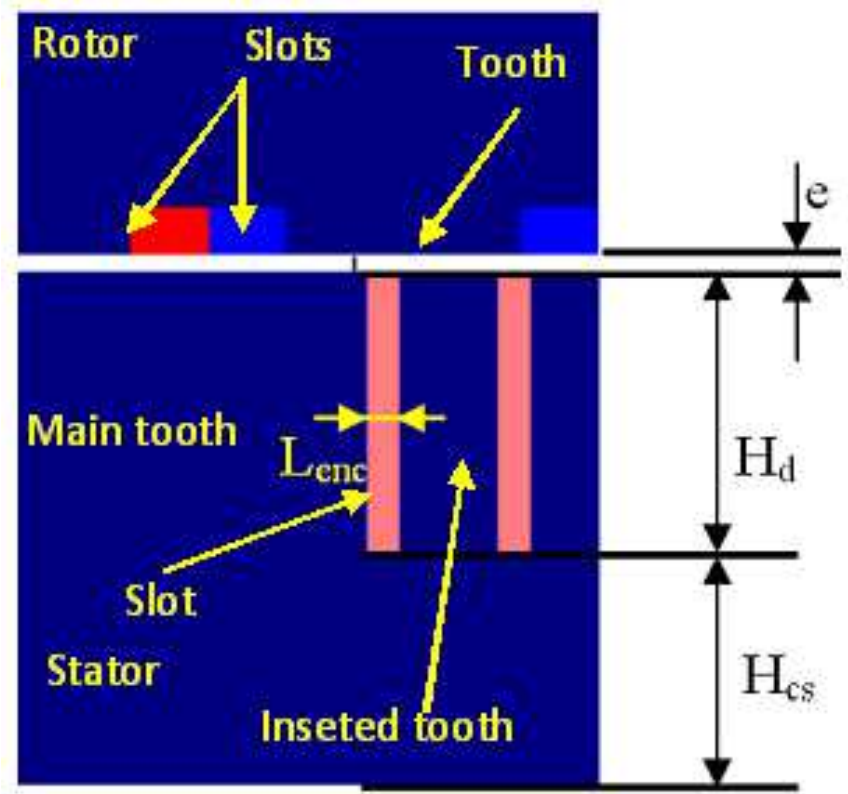

Where $R_{r}$ is the radius of the wheel, $M_{v}$ is the mass of the vehi-cle, $r_{d}$ is the reduction ratio, $g$ is the gravity force, $\lambda$ is the angle between the road and the horizontal and $\alpha_{t}$ is a coefficient taking in account of the coo-ling system to integrate, it is less than 1 .

The rated current can be deduced from the following relationship:

$$
\mathrm{I}_{\mathrm{dim}}=\frac{\mathrm{C}_{\mathrm{dim}}}{\mathrm{K}_{\mathrm{e}}}
$$

Where $\mathrm{K}_{\mathrm{e}}$ is the motor constant:

$$
\mathrm{K}_{\mathrm{e}}=2 \times \mathrm{n} \times \mathrm{N}_{\mathrm{s}} \times \frac{\mathrm{D}_{\mathrm{e}}^{2}-\mathrm{D}_{\mathrm{i}}^{\mathrm{e}}}{4} \times \mathrm{B}_{\mathrm{e}}
$$

Where $\mathrm{n}$ is the number of motor module, $\mathrm{D}_{\mathrm{e}}$ and $\mathrm{D}_{\mathrm{i}}$ are respectively the external and internal motor diameters, $\mathrm{N}_{\mathrm{s}}$ is the number of phase turn and $\mathrm{B}_{\mathrm{e}}$ is the flux density in the air-gap.

\section{Motor Sizing}

The figure 2 presents the different geometric parameters of the stator:

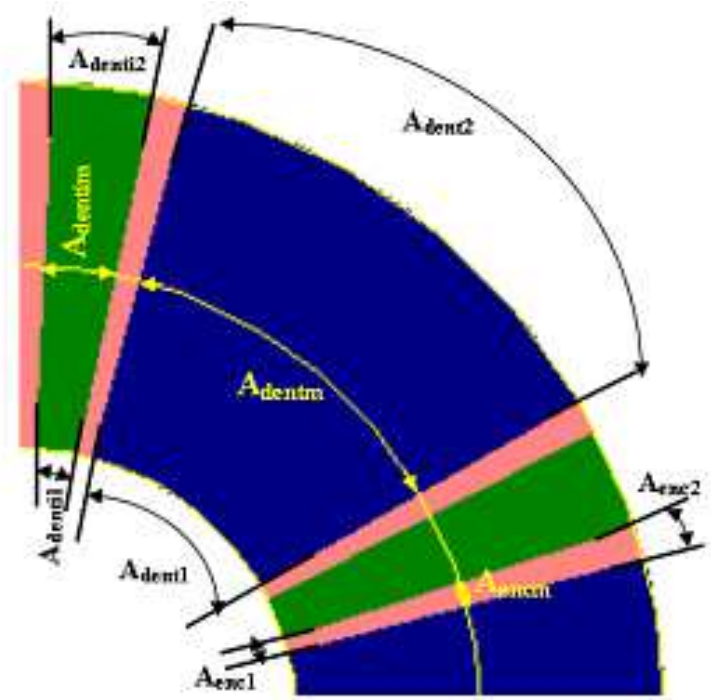

Figure 2. Geometric parameters of the stator.

The slot width of the stator is given by the following equation [4] and [5]:

$$
\mathrm{L}_{\mathrm{enc}}=\left(\frac{\mathrm{D}_{\mathrm{e}}+\mathrm{D}_{\mathrm{i}}}{2}\right) \sin \left(\frac{1}{2} \times\left(\frac{2 \times \pi}{\mathrm{N}_{\mathrm{d}}}-\alpha \times \beta \times \frac{\pi}{\mathrm{p}} \times\left(1-\mathrm{r}_{\mathrm{did}}\right)\right)\right)
$$

Where $D_{e}$ and $D_{i}$ are respectively the external and internal motor diameters, $N_{d}$ is the number of main teeth and $p$ is the number of poles pairs.
The lower angular width of stator slot is given by the following expression:

$$
A_{\text {enc1 }}=2 \times A \sin \left(\frac{\frac{L_{\text {enc }}}{2}}{\frac{D_{i}}{2}}\right)
$$

The superior angular width of stator slot is given by the following expression: 


$$
A_{\text {enc } 2}=2 \times A \sin \left(\frac{\frac{L_{\text {enc }}}{2}}{\frac{D_{e}}{2}}\right)
$$

The average angular width of a main tooth is expressed as follows:

$$
\mathrm{A}_{\mathrm{dentm}}=\alpha \times \beta \times \frac{\pi}{\mathrm{p}}
$$

The average angular width of the inserted tooth is expressed as follows:

$$
\mathrm{A}_{\text {dentim }}=\mathrm{r}_{\mathrm{did}} \times \mathrm{A}_{\mathrm{dentm}}
$$

The average angular width of the slot is expressed as follows:

$$
A_{\text {encm }}=\frac{1}{2} \times\left(\frac{2 \times \pi}{N_{d}}-A_{\text {dentm }}-A_{\text {dentim }}\right)
$$

The inferior angular width of stator main tooth is given by the following expression:

$$
\mathrm{A}_{\mathrm{dent} 1}=\mathrm{A}_{\mathrm{dentm}}+\mathrm{A}_{\mathrm{encm}}-\mathrm{A}_{\mathrm{dent} 1}
$$

The superior angular width of stator main tooth is given by the following expression:

$$
A_{\text {dent } 2}=A_{\text {dentm }}+A_{\text {encm }}-A_{\text {dent } 2}
$$

For the configurations with trapezoidal waveforms the height of a tooth is given by the following equation [2]:

$$
\mathrm{H}_{\mathrm{d}}=\frac{3 \times 2 \times \mathrm{N}_{\mathrm{s}}}{2 \times \mathrm{N}_{\mathrm{d}}} \times \frac{\mathrm{I}_{\mathrm{dim}}}{\delta} \times \frac{1}{\mathrm{~K}_{\mathrm{f}}} \times \frac{1}{\mathrm{~L}_{\mathrm{enc}}}
$$

Where $\mathrm{K}_{\mathrm{f}}$ is the filling factor of the slots, $\delta$ is the allowable current density in the slots, $\mathrm{I}_{\text {dim }}$ is the copper conductors sizing current and $\mathrm{N}_{\mathrm{s}}$ is the number of phase spires.

The calculation method of the dimensioning current is retailed in [4].

The heights of the stator yoke are derived by applying the theorem of conservation of flux between the main tooth and the stator yoke [5]:

$$
H_{c s}=\frac{B_{e}}{B_{c s}} \times \frac{\operatorname{Min}\left(S_{d}, S_{a}\right)}{2 \times\left(\frac{D_{e}-D_{i}}{2}\right)}
$$

Where $\mathrm{B}_{\mathrm{cs}}$ is the induction in the rotor yoke, $\mathrm{B}_{\mathrm{e}}$ is the flux density in the air-gap, $S_{d}$ is section of a stator tooth, $S_{a}$ is the section of a magnet for the MSAP structure or of the rotor tooth for the MSRB structure and $\mathrm{K}_{\mathrm{fu}}$ is the flux leakage coefficient

The figure 3 presents the different geometric parameters of the rotor.

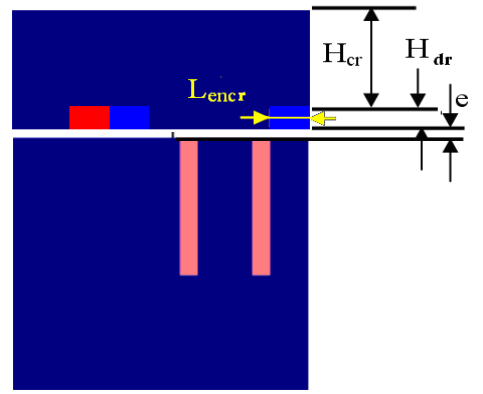

Figure 3. Different geometric parameters of the rotor.

- The middle width of a rotor slot is as:

$$
\mathrm{A}_{\mathrm{encmr}}=\gamma \times \mathrm{L}_{\mathrm{a}}
$$

- The slot width of these structures is given by the following equation [4] and [5]:

$$
\begin{gathered}
\mathrm{L}_{\text {encr }}=\left(\frac{\mathrm{D}_{\mathrm{e}}+\mathrm{D}_{\mathrm{i}}}{2}\right) \sin \left(\frac{\mathrm{A}_{\mathrm{encmr}}}{2}\right) \\
\mathrm{L}_{\mathrm{a}}=\frac{\pi}{\mathrm{p}} \times \beta
\end{gathered}
$$

With $\mathrm{L}_{\mathrm{a}}$ is the middle angular width of the magnet and $\gamma$ is a coefficient adjusted by finite element simulations with the help of the software Maxwell 2D and can be optimized.

- The average angular width of the rotor main tooth is expressed as follows:

$$
\mathrm{A}_{\mathrm{dentmr}}=\beta \times \frac{\pi}{\mathrm{p}} \times(1-2 \times \gamma)
$$

- The lower angular width of rotor slot is given by the following expression:

$$
A_{\text {encr } 1}=2 \times A \sin \left(\frac{\frac{L_{\text {encr }}}{2}}{\frac{D_{i}}{2}}\right)
$$

- The superior angular width of rotor slot is given by the following expression:

$$
A_{\text {encr } 2}=2 \times A \sin \left(\frac{\frac{L_{\text {encr }}}{2}}{\frac{D_{e}}{2}}\right)
$$

- The height of a rotor tooth $\mathrm{H}_{\mathrm{dr}}$ permitting to reserve the necessary space for the copper:

$$
\mathrm{H}_{\mathrm{dr}}=\frac{\mathrm{n} \times \mathrm{I}_{\mathrm{e}}}{\delta \times \mathrm{L}_{\mathrm{encr}}}
$$

Where $\mathrm{n}$ is the number of rotor coil spire, $\mathrm{I}_{\mathrm{e}}$ is the excitation current and $\delta$ is the admissible current density in the copper. 
Where $\mathrm{K}_{\mathrm{fu}}<1$ is the coefficient of flux leakages and e is the air-gap thickness.

Where $B_{c}$ is the induction of demagnetization, $B_{r}$ is the remanent induction of magnets and $\mu_{0}$ is the permeability of air.

The heights of the rotor yoke is derived by applying the theorem of conservation of flux between a magnet or rotor tooth and the rotor yoke [5]:

$$
H_{c r}=\frac{B_{e}}{B_{c r}} \times \frac{\operatorname{Min}\left(S_{d}, S_{a}\right)}{2 \times\left(\frac{D_{e}-D_{i}}{2}\right)} \times \frac{1}{K_{f u}}
$$

Where $\mathrm{B}_{\mathrm{cr}}$ is the induction in the rotor yoke.

\section{Back Electromotive Force}

The figure 4 represents the distribution of the vector induction to the level of the air-gap for the functioning at no load. The level of induction reaches the value calculated analytically.
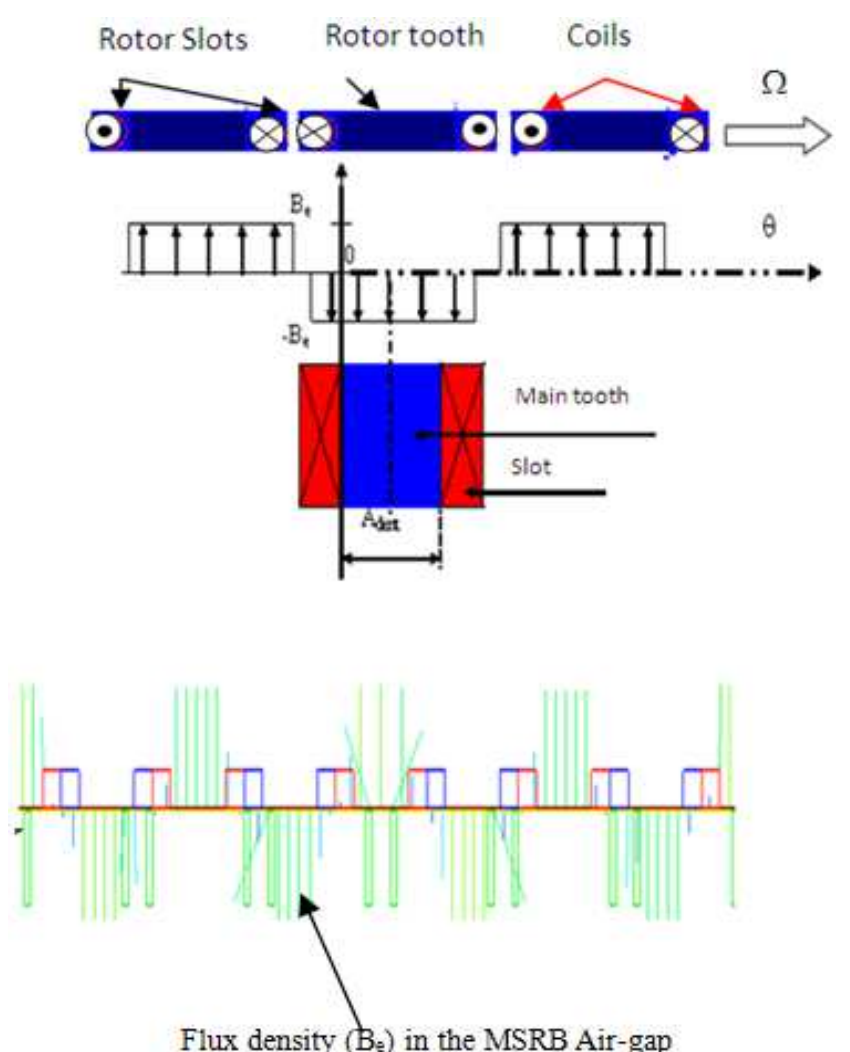

Figure 4. Initial position and induction in the air-gap.

From an initial position illustrated by figure 4 , rotor moves with angular velocity $(\Omega=d \theta / d t)$. Four distinct intervals appear according to magnets positions and geometrical parameters values defined previously. Table 2 illustrates these different intervals as well as flux variation. If $\alpha$ is equal to 1 , zone ' $a$ ' disappears. In the zone ' $b$ ', the flux decreases because a part of the magnet is not in front of the tooth. In the zone ' $c$ ', a magnet of an opposite polarity overlaps also the main tooth.
Consequently, the flux varies two times more quickly. Finally, the zone ' $d$ ' is identical to the zone ' $b$ '. These two zones exist only if the coefficient $\beta$ is less than 1 .

Table 2. Flux and electromotive force in function of motor parameters.

\begin{tabular}{llll}
\hline Zone & Position (rad) & Flux $\varphi_{\mathbf{b}}(\mathbf{W b})$ & $\operatorname{Emf}(\mathbf{V})$ \\
\hline a & $-\frac{\pi \beta}{2 \mathrm{p}}(1-\alpha) \leq \theta \leq \frac{\pi \beta}{2 \mathrm{p}}(1-\alpha)$ & $\frac{\left(\mathrm{D}_{\mathrm{e}}^{2}-\mathrm{D}_{\mathrm{i}}^{2}\right)}{8} \beta \frac{\pi}{\mathrm{p}} \alpha \mathrm{B} \mathrm{e}$ & $\mathbf{0}$ \\
b & $\frac{\pi \beta}{2 \mathrm{p}}(1-\alpha) \leq \theta \leq \frac{\pi}{\mathrm{p}}\left[1-\frac{\beta}{2}(1+\alpha)\right]$ & $\frac{\left(\mathrm{D}_{\mathrm{e}}^{2}-\mathrm{D}_{\mathrm{i}}^{2}\right)}{8}\left(\frac{\pi \beta}{2 \mathrm{p}}(1+\alpha)-\theta\right) \mathrm{B}_{\mathrm{e}}$ & $\mathrm{N}_{\mathrm{S}} \Omega \frac{\left(\mathrm{D}_{\mathrm{e}}^{2}-\mathrm{D}_{\mathrm{i}}^{2}\right)}{8} \mathrm{~B}_{\mathrm{e}}$ \\
C & $\frac{\pi}{\mathrm{p}}\left[1-\frac{\beta}{2}(1+\alpha)\right] \leq \theta \leq \frac{\pi \beta}{2 \mathrm{p}}(1+\alpha)$ & $\frac{\left(\mathrm{D}_{\mathrm{e}}^{2}-\mathrm{D}_{\mathrm{i}}^{2}\right)}{8}\left(\frac{\pi}{\mathrm{p}}-2 \theta\right) \mathrm{B} \mathrm{e}$ & $2 \mathrm{~N}_{\mathrm{S}} \Omega \frac{\left(\mathrm{D}_{\mathrm{e}}^{2}-\mathrm{D}_{\mathrm{i}}^{2}\right)}{8} \mathrm{~B}_{\mathrm{e}}$ \\
d & $\frac{\pi \beta}{2 \mathrm{p}}(1+\alpha) \leq \theta \leq \frac{\pi}{\mathrm{p}}\left[1-\frac{\beta}{2}(1-\alpha)\right]$ & $\frac{\left(\mathrm{D}_{\mathrm{e}}^{2}-\mathrm{D}_{\mathrm{i}}^{2}\right)}{8}\left(\frac{\pi}{\mathrm{p}}-\left[\frac{\pi \beta}{2 \mathrm{p}}(1+\alpha)\right]-\theta\right) \mathrm{B}_{\mathrm{e}}$ & $\mathrm{N}_{\mathrm{S}} \Omega \frac{\left(\mathrm{D}_{\mathrm{e}}^{2}-\mathrm{D}_{\mathrm{i}}^{2}\right)}{8} \mathrm{~B}_{\mathrm{e}}$ \\
\hline
\end{tabular}

The figure 5 presents the evolution of the flux and the electromotive force (e.m.f.) in function of electric angle

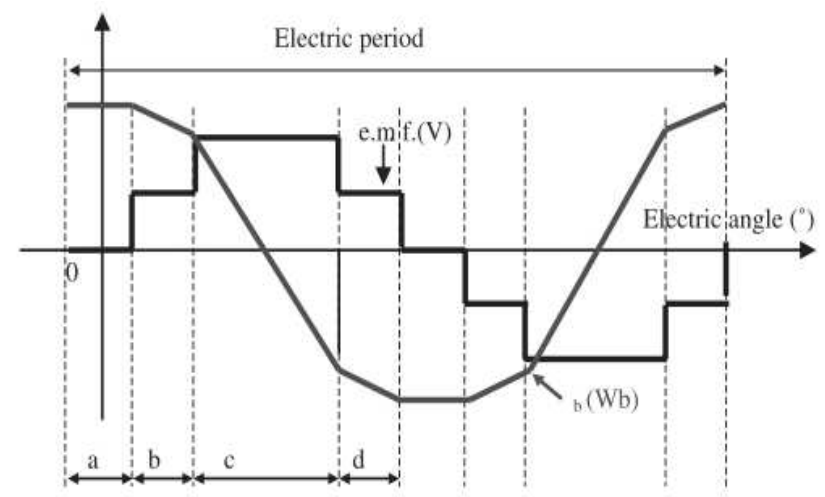

Figure 5. Flux and electromotive force in function of electric angle.

Le flux density in the air-gap is deduced from Ampere theorem:

$$
\mathrm{B}_{\mathrm{e}}=\frac{\mu_{0} \times \mathrm{n} \times \mathrm{I}_{\mathrm{e}}}{\mathrm{e}}
$$

Where $I_{e}$ is the excitation current, e is the Air-gap thickness, $\mu_{0}$ is the air permeability and $n$ is spires number of the rotor winding spires.

\section{Analytical Modeling of Inductance and Mutual Inductance}

\subsection{Analytical Modeling of Inductance}

For MSRB structures, phase inductance varies slightly in function of rotor position since the rotor slots are not deep. For these reasons, we consider that the MSRB structures is with smooth poles and the phase inductance is constant in linear regime. The figure 6 illustrates the distribution of the field lines to the level of a stator pole when the stator coil is supplied [11] and [12]. 


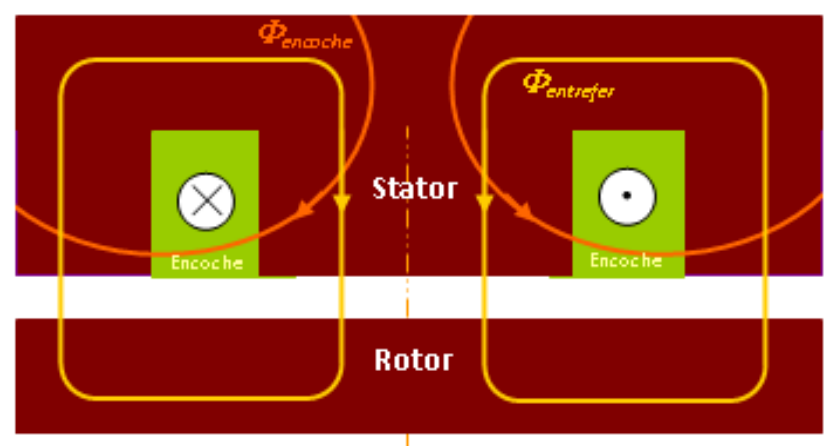

Figure 6. Distribution of the field lines for a powered coil.

This figure shows the presence of a flux leakages passing through the slot opening in a presence of leakage inductance in the slots copper, and of a main flux passing twice through the air gap and the magnet giving presence to an inductance of gap.

We recall the equations to model an inductance for a linear system:

$$
\begin{gathered}
\mathrm{L} \times \mathrm{i}_{1}=\mathrm{N}_{\mathrm{s}} \times \Phi_{1} \\
\Re \times \Phi_{1}=\mathrm{N}_{\mathrm{s}} \times \mathrm{i}_{1} \\
\mathrm{~L}=\frac{\mathrm{N}_{\mathrm{s}}^{2}}{\Re}
\end{gathered}
$$

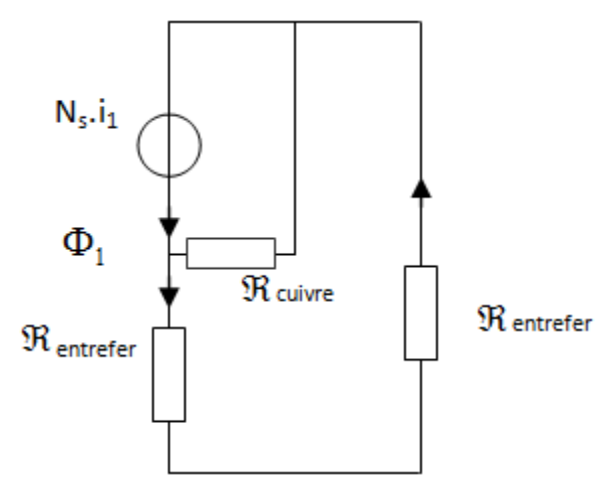

Figure 7. Network reluctance modeling inductance.

Where $\mathrm{L}$ is the inductance, $\mathrm{i}_{1}$ is the current of energize, $\mathrm{N}_{\mathrm{s}}$ is the number of spire and $\Phi_{1}$ is the flux giving birth to the $\mathrm{L}$ inductance and $\mathfrak{R}$ is the réluctance of the magnetic circuit.

The figure 7 illustrates the network of réluctance modeling the inductance of total phase of the motor [11] and [12].

According to this face, we can write:

$$
\mathrm{N}_{\mathrm{s}} \times \mathrm{i}_{1}=\left(2 \times \Re_{\text {entrefer }}\right) \times \Phi_{\text {entrefer }}=\Re_{\text {cuivre }} \times \Phi_{\text {encoche }}
$$

With the reluctance of the air gap and the copper are given by the following relationship [19]:

$$
\mathfrak{R}_{\text {entrefer }}=\frac{1}{\mu_{0}} \times \frac{\left(\mathrm{e}_{\mathrm{a}}\right)}{\frac{\mathrm{S}_{\mathrm{d}}}{2}}
$$

$$
\Re_{\text {cuivre }}=\frac{1}{\mu_{0}} \times \frac{\left(\mathrm{L}_{\mathrm{enc}}\right)}{\frac{\mathrm{D}_{\mathrm{e}}-\mathrm{D}_{\mathrm{i}}}{2} \times \mathrm{H}_{\mathrm{d}}}
$$

The model of the total inductance is deduced from equations (26), (27) and (28) [7], [8] and [9]:

$$
\begin{aligned}
& \mathrm{L}=\mathrm{L}_{\text {fuite }}+\mathrm{L}_{\text {entrefer }}=\frac{\mathrm{N}_{\mathrm{s}}^{2}}{\mathfrak{R}_{\text {cuivre }}}+\frac{\mathrm{N}_{\mathrm{s}}^{2}}{+2 \times \mathfrak{R}_{\text {entrefer }}} \\
& \mathrm{L}=\mu_{0} \times 2 \times \frac{\mathrm{N}_{\mathrm{s}}^{2}}{4}\left(\frac{\frac{\mathrm{S}_{\mathrm{d}}}{2}}{2 \times(\mathrm{e})}+\frac{\left(\frac{\mathrm{D}_{\mathrm{e}}-\mathrm{D}_{\mathrm{i}}}{2}\right) \times \mathrm{H}_{\mathrm{d}}}{\mathrm{L}_{\text {enc }}}\right)
\end{aligned}
$$

Where $S_{d}$ is the surface of the main tooth, $H_{d}$ is the height of the slot, $\mathrm{H}_{\mathrm{a}}$ is the height of the magnet, $\mathrm{L}_{\mathrm{enc}}$ is the width of the slot, e is the thickness of the air-gapr and $\mathfrak{R}$ is the reluctance.

\subsection{Analytical Modeling of Mutual Inductance}

The principle of the calculation of the mutual inductance rest on the supply of a coil for the calculation of the flux captured by the neighboring coil. The trajectory of the flux fixes the total reluctance of the magnetic circuit modeling this mutual inductance. The figure 8 illustrates the trajectory of the flux [8] and [9].

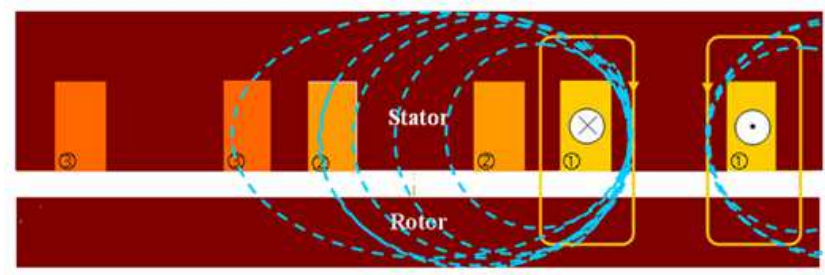

Figure 8. Distribution of the flux generated by the powered coil (1) and captured by adjacent coils.

From figure 8 we deduct the network of reluctance modeling the mutual inductance (figure 9) [8], [9].

Where $\mathfrak{R}_{1}$ is the reluctance of the air-gap in front of the tooth where the coil 1 is accommodated, $\mathfrak{R}_{2}$ are the reluctance of a main tooth, $\mathfrak{R}_{3}$ is the reluctance of the stator yoke, $\mathfrak{R}_{4}$ is the reluctance of the tooth where the coil 2 is accommodated, $\Re_{5}$ is the reluctance of the air-gap in front of the tooth (2) and $\mathfrak{R}_{6}$ is the reluctance of the rotor yoke.

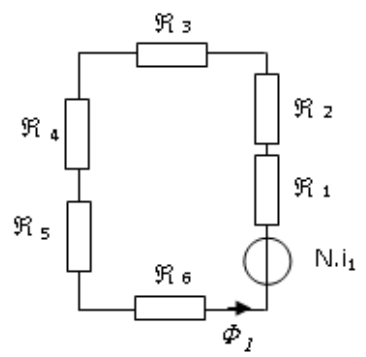

Figure 9. Network reluctance modeling mutual inductance. 
The expression of the mutual inductance is given by:

$$
\begin{gathered}
\mathrm{M}_{12} \times \mathrm{i}_{1}=\mathrm{N}_{\mathrm{s}} \times \Phi_{1} \\
\mathrm{M}_{12}=\frac{\mathrm{N}_{\mathrm{s}}{ }^{2}}{\mathfrak{R}}
\end{gathered}
$$

Where $\Phi_{1}$ is the flux captured by the coil (2) while energizing the coil (1), $i_{1}$ is the circulating current in the coil (1) and $\mathfrak{R}$ is the total reluctance.

The different mutual inductances of the motor are equal since the motor is symmetrical.

It comes then [8] and [9]:

$$
\begin{aligned}
& \Re_{1}=\frac{1}{\mu_{0}} \times \frac{(\mathrm{e})}{\frac{1}{2} \times\left(\frac{\mathrm{D}_{\mathrm{e}}-\mathrm{D}_{\mathrm{i}}}{2}\right) \times\left(\frac{\mathrm{D}_{\mathrm{e}}+\mathrm{D}_{\mathrm{i}}}{4}\right) \times \mathrm{A}_{\text {dentm }}} \\
& \mathfrak{R}_{2}=\frac{1}{\mu_{0}} \times \frac{2 \times \mathrm{H}_{\mathrm{d}}}{\mathrm{S}_{\mathrm{d}}} \\
& \mathfrak{R}_{3}=\frac{1}{\mu_{0} \times \mu_{\mathrm{r}}} \times \frac{\left(2 \times \mathrm{A}_{\text {encm }}+\frac{1}{2} \times \mathrm{A}_{\text {dentm }}+\mathrm{A}_{\text {dentim }}\right) \times \frac{\mathrm{D}_{\mathrm{e}}+\mathrm{D}_{\mathrm{i}}}{4}}{\mathrm{H}_{\mathrm{cs}} \times\left(\frac{\mathrm{D}_{\mathrm{e}}-\mathrm{D}_{\mathrm{i}}}{2}\right)} \\
& \mathfrak{R}_{4}=\frac{1}{\mu_{0}} \times \frac{2 \times \mathrm{H}_{\mathrm{d}}}{\mathrm{S}_{\mathrm{d}}} \\
& \Re_{5}=\frac{1}{\mu_{0}} \times \frac{(\mathrm{e})}{\frac{1}{2} \times\left(\frac{\mathrm{D}_{\mathrm{e}}-\mathrm{D}_{\mathrm{i}}}{2}\right) \times\left(\frac{\mathrm{D}_{\mathrm{e}}+\mathrm{D}_{\mathrm{i}}}{4}\right) \times \mathrm{A}_{\mathrm{dentm}}} \\
& \Re_{6}=\frac{1}{\mu_{0} \times \mu_{\mathrm{r}}} \times \frac{\left(2 \times \mathrm{A}_{\text {encm }}+\frac{1}{2} \times \mathrm{A}_{\text {dentm }}+\mathrm{A}_{\text {dentim }}\right) \times \frac{D_{\mathrm{e}}+\mathrm{D}_{\mathrm{i}}}{4}}{\mathrm{H}_{\mathrm{cs}} \times\left(\frac{\mathrm{D}_{\mathrm{e}}-\mathrm{D}_{\mathrm{i}}}{2}\right)}
\end{aligned}
$$

Where $A_{\text {encm }}$ is the middle width of the slot, $A_{\text {dentm }}$ is the middle width of the main tooth, $\mathrm{A}_{\text {dentim }}$ is the middle width of the inserted tooth, $\mathrm{H}_{\mathrm{cr}}$ is the height of the rotor yoke, $\mathrm{H}_{\mathrm{cs}}$ is the height of the stator yoke, $\mu_{0}$ is the absolute permeability and $\mu_{\mathrm{r}}$ is the relative permeability of the magnets.

One deducts a general expression of the mutual inductance of the motor wile neglecting the reluctance of iron:

$$
M=\mu_{0} \frac{\frac{S_{d}}{2}}{2 \times(e)} \frac{N_{s}^{2}}{4} \times 2
$$

\section{DC Bus Voltage}

The motor constant is defined by [9]:

$$
\mathrm{K}_{\mathrm{e}}=2 \times \mathrm{n} \times \mathrm{N}_{\mathrm{s}} \times \mathrm{A} \times \mathrm{B} \times \mathrm{B}_{\mathrm{g}}
$$

For the axial flux structures A and B are given by:

$$
\begin{gathered}
A=\frac{D_{e}-D_{i}}{2} \\
B=\frac{D_{e}+D_{i}}{2}
\end{gathered}
$$

Where $D_{e}$ and $D_{i}$ are respectively the external and the internal diameter of the axial flux motor, $\mathrm{N}_{\mathrm{s}}$ is the number of spire per phase, $\mathrm{n}$ is the module number and $\mathrm{B}_{\mathrm{g}}$ is the flux density in the air-gap.

The converter's continuous voltage $\mathrm{U}_{\mathrm{dc}}$ is calculated so that the vehicle can function at a maximum and stabilized speed with a weak torque undulation. The electromagnetic torque that the motor must exert at this operation point, via the mechanical power transmission system $\mathrm{T}_{\mathrm{Udc}}$ (reducing + differential) is estimated by the following expression:

$$
\mathrm{T}_{\mathrm{Udc}}=\frac{\mathrm{P}_{\mathrm{f}}}{\Omega}+\mathrm{T}_{\mathrm{d}}+\left(\mathrm{T}_{\mathrm{b}}+\mathrm{T}_{\mathrm{vb}}+\mathrm{T}_{\mathrm{fr}}\right)+\frac{\mathrm{T}_{\mathrm{r}}+\mathrm{T}_{\mathrm{a}}+\mathrm{T}_{\mathrm{c}}}{\mathrm{r}_{\mathrm{d}}}
$$

Where $T_{b}$ is the rubbing torque of the motor, $T_{v b}$ is the viscous rubbing torque of the motor, $\mathrm{T}_{\mathrm{fr}}$ is the fluid rubbing torque of the motor, $\mathrm{T}_{\mathrm{r}}$ is the torque due to the friction rolling resistance, $T_{a}$ is the torque due to the aerodynamic force, $T_{c}$ is the torque due to the climbing resistance, $T_{d}$ is the reducer losses torque and $\mathrm{P}_{\mathrm{f}}$ are the iron losses and $\Omega$ is the motor angular speed.

At this operation point, the phase current is given by the following relation:

$$
\mathrm{I}_{\mathrm{p}}=\frac{\mathrm{T}_{\mathrm{Udc}}}{\mathrm{K}_{\mathrm{e}}}
$$

The only possibility making it possible to reach the current value $I_{p}$ with a reduced undulation factor ( $10 \%$ for example) is to choose the converter's continuous voltage solution of the following equation [7-9]:

$$
\mathrm{r}=\frac{\mathrm{t}_{\mathrm{m}}}{\mathrm{t}_{\mathrm{p}}}=10 \%
$$

Where $t_{p}$ is the phase current maintains time at vehicle maximum speed and $t_{m}$ is the boarding time of the phase current from zero to $I_{p}[7-9]$ :

$$
\mathrm{t}_{\mathrm{m}}=-\frac{\mathrm{L}}{\mathrm{R}} \times \ln \left(1-\frac{2 \times \mathrm{R} \times \mathrm{I}_{\mathrm{p}}}{\mathrm{U}_{\mathrm{dc}}-\mathrm{K}_{\mathrm{e}} \times \Omega_{\max }}\right)
$$

Where $\mathrm{R}$ and $\mathrm{L}$ are respectively the phase resistance and inductance and $\Omega_{\max }$ is the maximum angular velocity of the motor.

The phase current maintains time at maximum speed of vehicle (corresponds to 120 electric degrees) is given by the following formula [7-9]:

$$
\mathrm{t}_{\mathrm{p}}=\frac{1}{3} \times \frac{2 \times \pi}{\mathrm{p} \times \Omega_{\max }}
$$


The converter's continuous voltage takes the following form [7-9]:

$$
\mathrm{U}_{\mathrm{dc}}=\frac{2 \times \mathrm{R} \times \mathrm{I}_{\mathrm{p}}}{1-\exp \left(-\frac{2 \times \pi \times \mathrm{r}}{3 \times \mathrm{p} \times \Omega_{\max } \times \frac{\mathrm{L}}{\mathrm{R}}}\right)}+\mathrm{K}_{\mathrm{e}} \times \Omega_{\text {max }}
$$

\section{Gear Ratio}

The electric motor is controlled by a low frequency electromagnetic converter [1-6]. For this raison the insertion of a gear speed amplifier with $r_{d}$ ratio is in the aims to enable the vehicle to reach the maximum speed of $80 \mathrm{~km} / \mathrm{h}$ in our application. This ratio also helps ensure proper interpolation of reference voltages in order to have a good quality of electromagnetic torque.

$$
\mathrm{r}_{\mathrm{d}}=\frac{2 \times \pi \times \mathrm{R}_{\mathrm{r}} \times \mathrm{F}_{\mathrm{ri}}}{\mathrm{n}_{\mathrm{qTA}} \times \mathrm{V}_{\max } \times \mathrm{p} \times \mathrm{n}_{\mathrm{iTR}}}
$$

Where $n_{i T R}$ is the reference voltages interpolation coefficient, $\mathrm{p}$ is the number of pair poles, $\mathrm{n}_{\mathrm{qTA}}$ is the coefficient of quality of the supply voltage, $\mathrm{F}_{\mathrm{ri}}$ is the switching frequency and $\mathrm{V}_{\max }$ is the maximum speed of the vehicle.

\section{Finite Element Validation}

The motor is studied in 2-D by FEM finite element software with geometric provided by the analytical model. The finite element model is based on cylindrical cut plan geometric representation at the average contour. Values of back electromotive force, electromagnetic torque, inductance and mutual inductance are very close to those found by the analytical method. In conclusion, the analytical modeling approach is validated entirely by the finite element method.

\section{Conclusion}

This paper describes a methodology of analytical sizing and modeling of a synchronous axial flux motor with wound rotor. The model is highly parameterized. It covers thereafter a wide power range by specification data changing according to the vehicle to size. This approach is validated by the finite element method. It then presents an effective design program of these types of motors.

\section{References}

[1] S. TOUNSI « Losses modelling of the electromagnetic and IGBTs converters », International Int. J. Electric and Hybrid Vehicles (IJEHV), Vol. 5, No. 1, 2013, pp:54-68.

[2] S. TOUNSI « Comparative study of trapezoïdal and sinusoïdal control of electric vehicle power train», International Journal of Scientific \& Technology Research (IJSTR), Vol. 1, Issue 10, Nov 2012.

[3] [M. HADJ KACEM, S. TOUNSI, R. NEJI «Systemic Design and Control of Electric Vehicles Power Chain », International Journal of Scientific \& Technology Research (IJSTR), Vol. 1, Issue 10, Nov 2012.

[4] S. TOUNSI «Control of the Electric Vehicles Power Chain with Electromagnetic Switches Reducing the Energy Consumption», Journal of Electromagnetic Analysis and Applications (JEMAA) Vol.3 No.12, December 2011.

[5] S. TOUNSI, M. HADJ KACEM et R. NEJI « Design of Static Converter for Electric Traction », International Review on Modelling and Similations (IREMOS) Volume 3, N. 6, December 2010, pp. 1189-1195.

[6] S. TOUNSI et R. NEJI: "Design of an Axial Flux Brushless DC Motor with Concentrated Winding for Electric Vehicles", Journal of Electrical Engineering (JEE), Volume 10, 2010 Edition: 2, pp. 134-146.

[7] S. TOUNSI, R. NEJI, and F. SELLAMI: "Design Methodology of Permanent Magnet Motors Improving Performances of Electric Vehicles", International Journal of Modelling and Simulation (IJMS), Volume 29, $\mathrm{N}^{\circ}$ 1, 2009.

[8] A. Moalla, S. TOUNSI et R. Neji: "Determination of axial flux motor electric parameters by the analytic-finite elements method", 1nd International Conference on Electrical Systems Design \& Technologies (ICEEDT'07), 4-6 Novembre, Hammamet, TUNISIA.

[9] N. Mellouli, S. TOUNSI et R. Neji: "Modelling by the finite elements method of a coiled rotor synchronous motor equivalent to a permanent magnets axial flux motor", 1nd International Conference on Electrical Systems Design \& Technologies (ICEEDT'07), 4-6 Novembre, Hammamet, TUNISIA. 